\title{
Determination of crude oil thickness at night using thermal imagery
}

\author{
Toomas H. Allik
}

Active EO Inc., Alexandria, VA

October 10, 2018

\begin{abstract}
A heat transfer model, has determined millimeter crude oil thicknesses on saltwater at night. Model inputs are calibrated thermographic imagery, weather station data, metrological observations, and crude oil thermal conductivity. Outdoor field-testing was performed at the National Oil Spill Response \& Renewable Energy Test Facility (Ohmsett) to determine model accuracy. Alaskan North Slope (ANS), Hoover Offshore Oil Pipeline System Blend (HOOPS), and ROCK crude oils were placed at varying $\mathrm{mm}$ depths. A roof-top mounted thermal camera measured the average oil surface temperature for each target and converted to oil spill thickness. The fidelity of the thickness measurements is dependent on the accurate measurement of the atmospheric and weather parameters, sea state, heat transfer constants, crude oil evaporation rates, and calibration and stability of the thermal camera.
\end{abstract}

Keywords: remote sensing; oil spill thickness measurement; night heat transfer model

\section{Introduction}

Remote sensing of oil slick thickness in a marine environment is an active area of research and development [1-5]. Although significant advances have been made, many airborne ultraviolet, visible, near infrared (NIR) and short-wave infrared (SWIR) oil spill sensors do not work well under degraded visual environments (DVE) such as darkness, fog, smoke, and clouds, nor provide a consistent measure of extreme oil thickness. These electro-optic (EO) sensors can be expensive, heavy, costly and labor-intensive to operate from both the platform and the sensor payload perspective, and may provide a limited single point capability [1-7]. When discussing the challenges of measuring oil slick thickness, Fingas could not find consistent spectral signatures to gauge oil slick thickness [1]. In contrast, the long wave infrared (LWIR) atmospheric window has been used for the identification of millimeter oil spills [8-12]. Oil spill detection with uncooled, inexpensive microbolometers is well established and relies on capturing thermal radiation, not filtered spectra. Quantification of crude oil spill thickness with thermal remote sensing cameras had been up for debate [13,14].

This quantitative study determines the thickness from calibrated thermal emission. At night, thermal contrast is seen due to the lower emissivity of crude oil $\left(\varepsilon_{0}=96 \%\right)$ versus water $\left(\varepsilon_{w}=99 \%\right)$ and heat transfer mechanisms [10]. The night heat transfer model includes radiation, conduction and convection terms [15]. It estimates oil thickness (L) from oil surface ( $\left.\mathrm{T}_{\mathrm{os}}\right)$ and water surface $\left(\mathrm{T}_{\mathrm{ws}}\right)$ temperatures obtained from a LWIR camera, and air $\left(\mathrm{T}_{\mathrm{a}}\right)$ and water $\left(\mathrm{T}_{\mathrm{w}}\right)$ temperatures obtained from a weather station datalogger. Night sky radiation cooling is included in the model and is calculated from metrological inputs of cloud cover (C), cloud altitudes (K), and relative humidity (RH). When implemented into practice, this remote sensing technique can allow oil spill responders to map oil spill thickness, in near real time, with a low SWAP-C sensor [12].

\section{Materials and Methods}

Night field tests were performed at the Ohmsett outdoor saltwater pool to provide data for the model. Figure 1 is a day picture of the target scene from the perspective of the thermal camera, located on an 
adjacent third story roof top. The crude oils were contained on a stationery target raft containing surfacefloating, $1.5 \mathrm{~m}$ diameter rings constructed of two-inch, flexible, black poly-pipe. The circular rings had a full circumference polymeric skirt that extended 10 to $15 \mathrm{~cm}$ below and above the surface. These skirts contained the oils in windy conditions and minimized oil loss and cross contamination. Alaskan North Slope (ANS), Hoover Off-shore Oil Pipeline System (HOOPS), and ROCK Crude (Eastern Canada) crude oils were tested. Viewing Figure 1, ANS is on the bottom row, HOOPS in the middle, and ROCK Crude in the third row from the bottom. To deliver the desired thickness, the surface area of the ring was calculated and an appropriate volume of oil was measured and delivered with a large graduate cylinder. The thicker $(12.5 \mathrm{~mm})$ oils were on the left, $6.25 \mathrm{~mm}$ thick in the middle, and thinnest $(2.5 \mathrm{~mm})$ on the right. Visual inspection of the oil targets could not determine oil thickness. The night tests were performed 3.5 days after the crude oil were loaded in the rings. Evaporation of the volatile, low molecular weight components reduces the oil depth. Fingas provides the equation for ANS evaporation rate (Ev\%) in Eq. 1 [3];

$$
\mathrm{Ev} \%=(2.86+0.045 \mathrm{~T}) \ln (\mathrm{t})
$$

where $\mathrm{T}$ is the temperature in degrees Celsius and $\mathrm{t}$ is the time in minutes. During the test week, the Ohmsett tank averaged $8^{\circ} \mathrm{C}$. Assuming the same Ev\% for HOOPS and ROCK, the oil thicknesses during the night tests would be approximately 9,4 , and $2 \mathrm{~mm}$. Although the target oil thicknesses are stated above, it should be noted that the spread of oil is very dependent upon a number of variables including degree of weathering, temperature, interfacial tension with the water, viscosity, density, rain fall and wind conditions. These factors affect the localized oil thicknesses experienced at any given time.

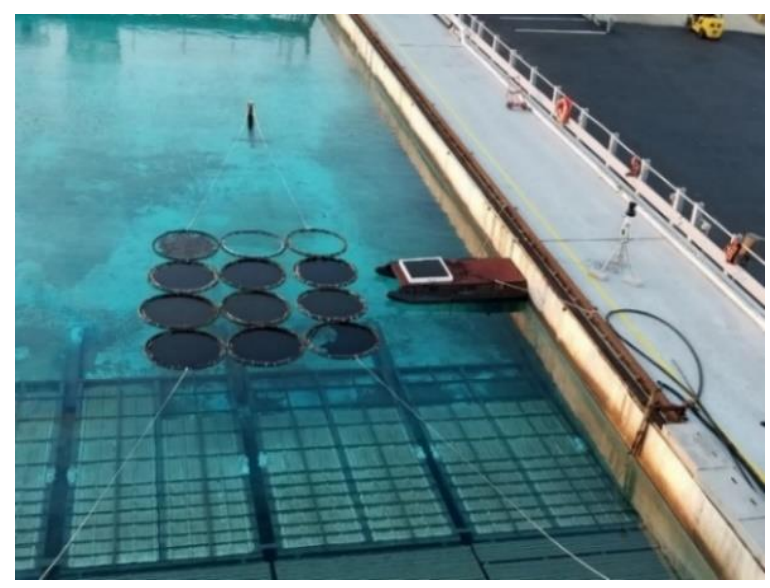

Figure 1. Photograph of the experimental set-up at Ohmsett, showing crude oils contained in $1.5 \mathrm{~m}$ diameter rings, blackbody calibration source, and weather station.

The FLIR T640SC camera, with a $25^{\circ}$ field-of-view, viewed the full width of the target raft. The 0.69 milliradian instantaneous field-of-view provided a $1.7 \mathrm{~cm}$ ground sampling distance at the $25 \mathrm{~m}$ standoff range. The quoted thermal sensitivity (NEDT) of the recently calibrated FLIR camera was $<30 \mathrm{mK} @ 30^{\circ} \mathrm{C}$. LWIR imagery was collected at 10-minute intervals. In addition, a LWIR camera (MARINE SCOUT) mounted on a DJI Matrice Pro 600 UAV was flow over the crude oil targets enabled, via post-processing, the measurement of oil thickness [12]. The Onset HOBO H21-USB Micro Station data logger provided sea truthing, was placed near the targets, and measured $\mathrm{T}_{\mathrm{a}}, \mathrm{T}_{\mathrm{w}}$, and $\mathrm{RH} \%$. The Onset temperature sensors provided $< \pm 0.2^{\circ} \mathrm{C}$ total accuracy and resolution of $< \pm 0.03^{\circ} \mathrm{C}$ over the range of temperatures. A $1 \mathrm{~m}^{2}$ blackbody emitter $\left(1 / 8^{\prime \prime}\right.$ thick aluminum painted with Krylon ultra-flat black paint and insulated with Styrofoam on the back surface) was floated on a second raft near the crude oils and its temperature (Tbb) 
was monitored by the data logger also. $\mathrm{T}_{\mathrm{bb}}$ and $\mathrm{T}_{\mathrm{ws}}$ measurements provided useful LWIR camera temperature calibrations during the field test. Shown in Figure 2 are typical night thermal images where the thickness contrast is obvious. It is difficult to rely on thermal imagery, by itself, to determine oil slick thickness. Additional modeling and sea truth data is required.
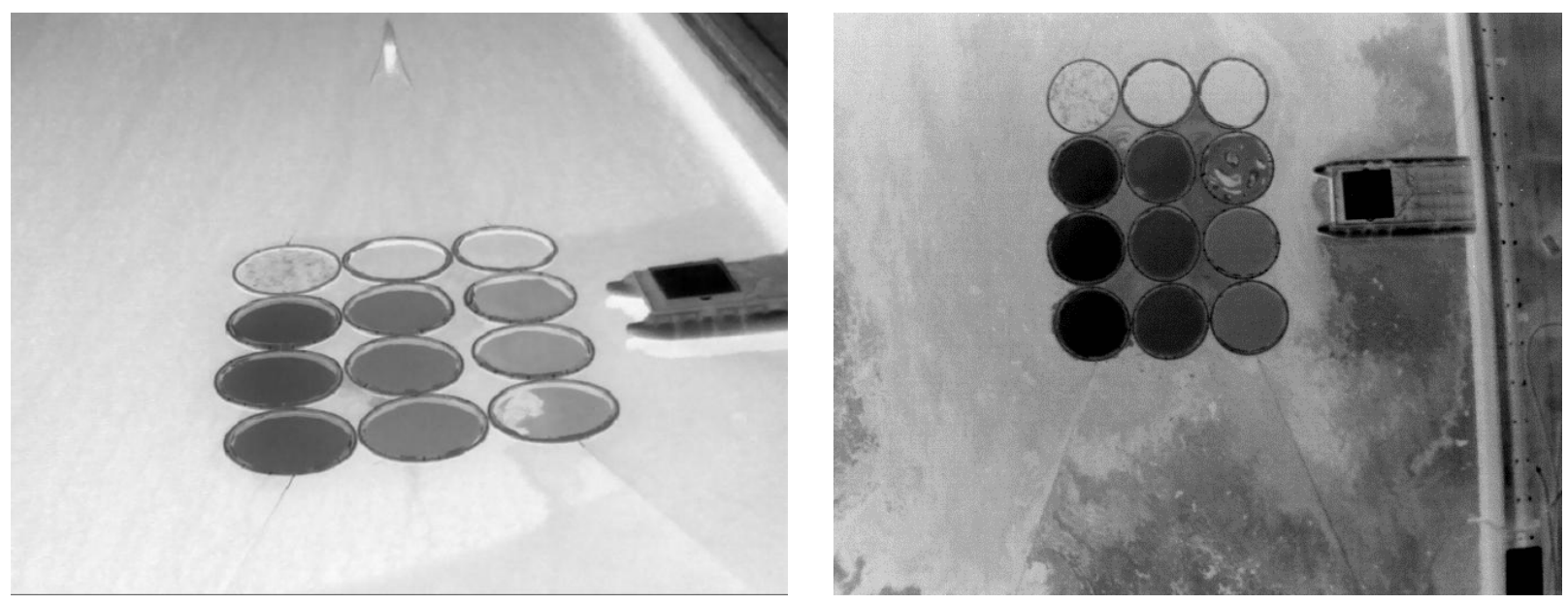

Figure 2. Night LWIR images of three crude oils at various thicknesses (thicker on left column, thinner on right). Left image was taken from adjacent roof-top, and right image was taken from 50' altitude UAV.

\section{Results, Modeling and Discussion}

FLIR ResearchIR Max 4 thermal analysis software and Mathcad were used to create regions of interests (ROIs) and average $\mathrm{T}_{\mathrm{os}}$ and $\mathrm{T}_{\mathrm{ws}}$ were calculated. The ROI size and location were adjusted to account for small raft movements. Table 1 show night weather station data and ROI crude oil temperatures for a twohour window near midnight. This evening window would allow enough time for a trained analysist to perform calculations for the next morning. The few $\mathrm{K}$ temperature differentials between the thin and thick Tos is resolvable with the thermal camera. The apparent surface temperatures of the crude oils and saltwater were converted into real temperatures by adjusting for emissivity.

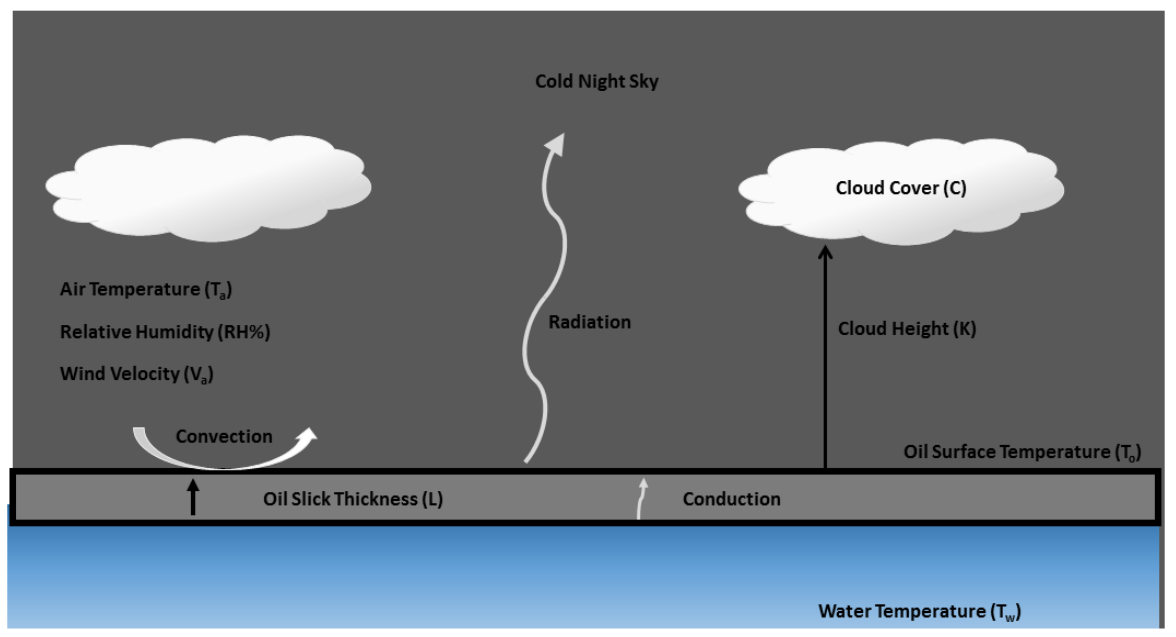

Figure 3. Night heat transfer model to predict oil thickness. 
Table 1. Averaged weather station, crude oil surface $\left(\mathrm{T}_{\mathrm{os}}\right)$ and water surface $\left(\mathrm{T}_{\mathrm{ws}}\right)$ temperatures used for night oil thickness calculations

\begin{tabular}{|c|c|c|c|c|c|c|c|c|c|c|c|c|c|c|}
\hline & $\begin{array}{l}\text { Air } \\
\text { Temp }\end{array}$ & RH & $\begin{array}{l}\text { Water } \\
\text { Temp }\end{array}$ & $\begin{array}{c}\text { Surface } \\
\text { Water Temp }\end{array}$ & $\begin{array}{c}\text { Blackbody } \\
\text { Temp }\end{array}$ & $\begin{array}{l}\text { ANS } \\
9 \mathrm{~mm}\end{array}$ & $\begin{array}{l}\text { ANS } \\
4 \mathrm{~mm}\end{array}$ & $\begin{array}{l}\text { ANS } \\
2 \mathrm{~mm}\end{array}$ & $\begin{array}{l}\text { HOOPS } \\
9 \mathrm{~mm}\end{array}$ & $\begin{array}{c}\text { HOOPS } \\
4 \mathrm{~mm}\end{array}$ & $\begin{array}{l}\text { HOOPS } \\
2 \mathrm{~mm}\end{array}$ & $\begin{array}{l}\text { ROCK } \\
9 \mathrm{~mm}\end{array}$ & $\begin{array}{l}\text { ROCK } \\
4 \mathrm{~mm}\end{array}$ & $\begin{array}{l}\text { ROCK } \\
2 \mathrm{~mm}\end{array}$ \\
\hline Date and Time & $\mathrm{Ta}_{\mathrm{a}}$ & $\%$ & $\mathrm{~T}_{\mathrm{w}} \mathrm{T}$ & $\mathbf{T}_{\mathrm{ws}}$ & $\mathrm{Tbb}^{\mathrm{T}}$ & $\mathrm{T}_{\mathrm{os}}$ & $\mathrm{T}_{\mathrm{os}}$ & $\mathrm{T}_{\text {os }}$ & Tos & $T_{\text {os }}$ & Tos & Tos & Tos & Tos \\
\hline Units & K & $\%$ & K & K & K & K & K & K & K & K & K & K & K & K \\
\hline 12/6/2017 22:36 & 276.9 & 48.6 & 281.2 & 276.3 & 272.9 & 273.1 & 274.4 & 275.3 & 272.8 & 274.0 & 275.4 & 272.8 & 274.0 & 275.2 \\
\hline 12/6/2017 22:46 & 277.0 & 47.9 & 281.2 & 276.2 & 273.2 & 273.2 & 274.4 & 275.3 & 272.8 & 274.0 & 275.2 & 272.8 & 273.9 & 275.1 \\
\hline 12/6/2017 22:56 & 277.1 & 47.4 & 281.2 & 276.2 & 273.6 & 273.3 & 274.5 & 275.3 & 272.9 & 274.1 & 275.2 & 272.9 & 273.9 & 275.1 \\
\hline 12/6/2017 23:06 & 277.0 & 47.7 & 281.2 & 276.3 & 273.7 & 273.3 & 274.5 & 275.3 & 272.9 & 274.1 & 275.3 & 272.9 & 273.9 & 275.1 \\
\hline 12/6/2017 23:16 & 277.0 & 47.6 & 281.2 & 276.2 & 274.1 & 273.4 & 274.6 & 275.3 & 273.1 & 274.1 & 275.4 & 273.0 & 274.0 & 275.2 \\
\hline 12/6/2017 23:26 & 277.0 & 47.7 & 281.2 & 276.2 & 274.1 & 273.4 & 274.5 & 275.3 & 273.1 & 274.1 & 275.3 & 273.0 & 274.0 & 275.1 \\
\hline 12/6/2017 23:36 & 276.8 & 48.6 & 281.2 & 276.2 & 274.1 & 273.2 & 274.4 & 275.3 & 272.9 & 274.1 & 275.3 & 272.9 & 274.0 & 275.2 \\
\hline 12/6/2017 23:46 & 276.7 & 48.8 & 281.2 & 276.4 & 274.1 & 273.5 & 274.6 & 275.4 & 273.1 & 274.2 & 275.4 & 273.1 & 274.1 & 275.3 \\
\hline 12/6/2017 23:56 & 276.6 & 49.8 & 281.2 & 276.6 & 274.1 & 273.3 & 274.3 & 275.1 & 273.0 & 273.9 & 275.1 & 272.9 & 273.9 & 274.9 \\
\hline 12/7/2017 0:06 & 276.5 & 50.6 & 281.2 & 276.2 & 273.9 & 273.1 & 274.2 & 275.0 & 272.7 & 273.8 & 275.0 & 272.7 & 273.7 & 274.8 \\
\hline 12/7/2017 0:16 & 276.6 & 50.6 & 281.2 & 276.9 & 273.9 & 272.7 & 273.9 & 274.7 & 272.2 & 273.4 & 274.7 & 272.1 & 273.1 & 274.5 \\
\hline 12/7/2017 0:26 & 276.4 & 51.6 & 281.2 & 276.8 & 273.4 & 272.4 & 273.6 & 274.4 & 272.0 & 273.1 & 274.6 & 271.9 & 273.0 & 274.3 \\
\hline 12/7/2017 0:36 & 276.4 & 51.8 & 281.1 & 276.3 & 273.1 & 272.0 & 273.0 & 274.1 & 271.5 & 273.0 & 274.5 & 271.5 & 272.5 & 274.3 \\
\hline
\end{tabular}


Shown in Figure 3 is a schematic night heat transfer model to predict oil slick thickness on water. The model predicts L using infrared thermography, oil thermal conductivity, and metrological data. There are three heat transfer mechanisms: conduction (Fourier's Law), convection (Newton's Law of Cooling) and radiation (Stefan-Boltzmann Law) [15] in the night heat transfer model for crude oil depth along with night sky radiation cooling [16-18]. The heat flux equations, $\mathrm{q}^{\prime \prime}\left(\mathrm{W} / \mathrm{m}^{2}\right)$ are the following:

$$
\begin{gathered}
\mathrm{q}^{\prime \prime} \text { Conduction }=\mathrm{k}_{\mathrm{o}}\left(\mathrm{T}_{\mathrm{ob}}-\mathrm{T}_{\mathrm{os}}\right) / \mathrm{L} \\
\mathrm{q}^{\prime \prime} \text { Convection }=\mathrm{h}_{\mathrm{o}}\left(\mathrm{T}_{\mathrm{a}}-\mathrm{T}_{\mathrm{os}}\right) \\
\mathrm{q}^{\prime \prime} \text { Radiation }=\varepsilon_{o} \sigma\left(\mathrm{T}_{\mathrm{o}}^{4}\right)
\end{gathered}
$$

where $\mathrm{T}_{\mathrm{ob}}$ is the is the oil temperature at the water interface, and $\sigma$ is the Stefan-Boltzmann constant $(5.67 \mathrm{x}$ $\left.10^{-8} \mathrm{~W} / \mathrm{m}^{2} \mathrm{~K}^{4}\right)$. Thermal conductivity $\left(\mathrm{k}_{\mathrm{o}}\right)$ was measured by Dynalene Laboratory Services for the three oils using transient line heat source methodology. The ko values were: ANS $(0.126 \mathrm{~W} / \mathrm{m}(\mathrm{K}))$, HOOPS $(0.127 \mathrm{~W} / \mathrm{m}(\mathrm{K}))$ and ROCK $(0.135 \mathrm{~W} / \mathrm{m}(\mathrm{K}))$. The air convection coefficient $\left(\mathrm{h}_{\mathrm{o}}\right)$ was not known for the skirted ring sample geometry and was approximated as $1.7 \mathrm{~W} / \mathrm{m}^{2} \mathrm{~K}$ [15].

At night, the oil will emit infrared radiation (heat) to the very low temperature night sky heat sink. This is observed as frost on a car windshield or plants during a clear night when $\mathrm{T}_{\mathrm{a}}$ is above $0^{\circ} \mathrm{C}$. Note Table 1, where $\mathrm{T}_{\mathrm{bb}}$ is significantly lower than $\mathrm{T}_{\mathrm{a}}$ and $\mathrm{T}_{\mathrm{ws}}$, confirming the metrological observations. Goforth et al. have developed a night sky radiation cooling equation that is dependent on cloud cover and humidity, and is known as the modified Swinbank model, Eq. (5) [18]:

$$
\mathrm{q}^{\prime \prime} \text { Thermal Night Sky }=\left[\left(1+\mathrm{KC}^{2}\right) \times 8.78 \times 10^{-13} \times \mathrm{T}^{5}{ }^{5.852} \times \mathrm{RH}^{0.07195}\right]
$$

where $\mathrm{K}$ is 0.34 for cloud height $<2 \mathrm{~km}, 0.18$ for cloud height between $2 \mathrm{~km}$ and $5 \mathrm{~km}$, and 0.06 for height $>5 \mathrm{~km}$. C ranges from 0 for clear sky, through 1.0 for totally overcast, and $\mathrm{RH}$ is measured in percent $[18,19]$.

For the case where $T_{w}>T_{a}$, accounting for night radiative cooling, and applying the conservation of energy $\left(E_{\text {in }}=E_{\text {out }}\right)$, the energy balance equation is:

$$
\mathrm{k}_{\mathrm{o}}\left(\mathrm{T}_{\mathrm{ob}}-\mathrm{T}_{\mathrm{os}}\right) / \mathrm{L}+\mathrm{h}_{\mathrm{o}}\left(\mathrm{T}_{\mathrm{a}}-\mathrm{T}_{\mathrm{os}}\right)=\varepsilon \sigma\left(\mathrm{T}_{\text {os }}^{4}\right)-\left[\left(1+\mathrm{KC}^{2}\right) \times 8.78 \times 10^{-13} \times \mathrm{T}^{5.852} \times \mathrm{RH}^{0.07195}\right]
$$

It is difficult to remotely measure $\mathrm{T}_{\mathrm{ob}}$, and the assumption made is that its temperature is close to $\mathrm{T}_{\mathrm{ws}}$ ( $\mathrm{T}_{\mathrm{ob}} \approx$ $\left.\mathrm{T}_{\mathrm{ws}}\right)$. Rearranging and solving for $\mathrm{L}$, the oil thickness at night is approximated by Eq. (7).

$$
\mathrm{L} \approx \frac{\mathrm{k}_{\mathrm{o}}\left(\mathrm{T}_{\mathrm{ws}}-\mathrm{T}_{\mathrm{os}}\right)}{\varepsilon \sigma\left(\mathrm{T}_{\mathrm{os}}{ }^{4}\right)-\left[\left(1+\mathrm{KC}^{2}\right) \times 8.78 \times 10^{-13} \times \mathrm{T}^{5.852} \times \mathrm{RH}^{0.07195}\right]-\mathrm{h}_{\mathrm{o}}\left(\mathrm{T}_{\mathrm{a}}-\mathrm{T}_{\mathrm{os}}\right)}
$$

At night, thicker oils have lower temperatures than their thinner counterparts. Table 2 shows ANS, HOOPS and ROCK crude oil thickness and standard deviations for night measurements. For this analysis, $\mathrm{K}$ was set to 0.06 and $\mathrm{C}$ was 0.1 . The results show order-of-magnitude agreement between calculations and the crude oil placed in the rings for this relatively calm and clear night. 


\section{6 of 8}

Table 2. Results of oil thickness calculations for night measurements

\begin{tabular}{|c|c|c|c|c|c|c|c|c|c|}
\hline & $\begin{array}{c}\text { ANS } \\
\text { Thickness }\end{array}$ & $\begin{array}{c}\text { ANS } \\
\text { Thickness }\end{array}$ & $\begin{array}{c}\text { ANS } \\
\text { Thickness }\end{array}$ & $\begin{array}{l}\text { HOOPS } \\
\text { Thickness }\end{array}$ & $\begin{array}{l}\text { HOOPS } \\
\text { Thickness }\end{array}$ & $\begin{array}{l}\text { HOOPS } \\
\text { Thickness }\end{array}$ & $\begin{array}{c}\text { ROCK } \\
\text { Thickness }\end{array}$ & $\begin{array}{c}\text { ROCK } \\
\text { Thickness }\end{array}$ & $\begin{array}{c}\text { ROCK } \\
\text { Thickness }\end{array}$ \\
\hline Date and Time & $9 \mathrm{~mm}$ & $4 \mathrm{~mm}$ & $2 \mathrm{~mm}$ & $9 \mathrm{~mm}$ & $4 \mathrm{~mm}$ & $2 \mathrm{~mm}$ & $9 \mathrm{~mm}$ & $4 \mathrm{~mm}$ & $2 \mathrm{~mm}$ \\
\hline $12 / 6 / 2017$ 22:36 & 5.8 & 3.1 & 1.5 & 6.7 & 3.8 & 1.4 & 6.7 & 3.9 & 1.6 \\
\hline 12/6/2017 22:46 & 5.5 & 3.0 & 1.5 & 6.4 & 3.8 & 1.5 & 6.5 & 4.0 & 1.7 \\
\hline $12 / 6 / 2017$ 22:56 & 5.3 & 2.8 & 1.3 & 6.2 & 3.6 & 1.5 & 6.4 & 3.9 & 1.7 \\
\hline 12/6/2017 23:06 & 5.5 & 3.0 & 1.6 & 6.4 & 3.8 & 1.6 & 6.5 & 4.1 & 1.9 \\
\hline 12/6/2017 23:16 & 5.0 & 2.7 & 1.3 & 5.8 & 3.5 & 1.3 & 5.9 & 3.7 & 1.6 \\
\hline $12 / 6 / 2017$ 23:26 & 5.0 & 2.7 & 1.5 & 5.7 & 3.6 & 1.4 & 5.8 & 3.8 & 1.7 \\
\hline 12/6/2017 23:36 & 5.4 & 2.9 & 1.5 & 6.1 & 3.6 & 1.4 & 6.1 & 3.8 & 1.6 \\
\hline 12/6/2017 23:46 & 5.2 & 2.9 & 1.5 & 5.9 & 3.6 & 1.5 & 6.0 & 3.8 & 1.7 \\
\hline 12/6/2017 23:56 & 5.8 & 3.7 & 2.2 & 6.6 & 4.5 & 2.3 & 6.8 & 4.6 & 2.6 \\
\hline 12/7/2017 0:06 & 5.6 & 3.2 & 1.9 & 6.5 & 4.1 & 1.8 & 6.5 & 4.3 & 2.2 \\
\hline 12/7/2017 0:16 & 7.8 & 5.0 & 3.5 & 9.1 & 6.2 & 3.5 & 9.4 & 6.8 & 3.9 \\
\hline 12/7/2017 0:26 & 8.5 & 5.5 & 3.8 & 9.5 & 6.5 & 3.5 & 9.7 & 6.8 & 4.0 \\
\hline 12/7/2017 0:36 & 8.6 & 5.9 & 3.6 & 9.8 & 5.9 & 3.0 & 10.0 & 7.0 & 3.2 \\
\hline Average & 6.1 & 3.6 & 2.0 & 7.0 & 4.4 & 2.0 & 7.1 & 4.6 & 2.3 \\
\hline Standard Deviation & 1.3 & 1.1 & 0.9 & 1.5 & 1.1 & 0.8 & 1.5 & 1.3 & 0.9 \\
\hline
\end{tabular}




\section{Conclusions}

EO imagers that rely on reflected solar radiation to detect and quantify oil spills, can have degraded performance at low and varying light levels. However, a heat transfer model coupled with thermal radiometric cameras, low-cost weather stations, observed metrological data can remotely determine oil spill thickness at night. The fidelity of the calculation is dependent on the accurate measurement of the experimental parameters, temperature calibration of the LWIR camera, evaporation rates under these field test conditions, and values of the heat transfer constants. Additional refinements to the heat transfer model may yield more accurate results. The addition of water currents and waves to the model would be beneficial.

For future oil exploration at remote northern locations, disasters, terrorist activities were where lives are at stake, oil spill detection, containment, treatment, recovery and cleanup must offer nearreal time, 24/7 exploitation of collected data. In general, many night operations are not encouraged among industry and regulatory groups [19]. However, night-time surveillance can be performed by highly skilled pilots and operators. This is highly desirable for government agencies tracking clean up performance when Responsible Parties (RPs), Oil Spill Response Organizations (OSROs) and Vessels of Opportunity (VOOs) and their crews have completed their day's tasks and have left the scene. Most EO platforms on existing vessels, fixed wing, rotary and UAV assets have thermal cameras. These cameras are typically used for navigation and oil spill detection. The implementation of these demonstrated algorithms, along with accurate sea truthing, will allow quantification of oil spill thickness. The creation of near real-time, oil spill thickness maps from the previous night has operation appeal.

Funding: This study was funded in part by the U.S. Department of the Interior, Bureau of Safety and Environmental Enforcement, through an interagency agreement with the U.S. Army Research Development and Engineering Command.

Acknowledgments: Portions of this work were presented at the SPIE Ocean Sensing and Monitoring X Conference in 2018, "Remote measurement of thick oil spill depth using thermal imagery" and "Mapping and reconnaissance imager, night-enhanced, for sensing of contaminants, oil, and unseen threats (MARINE SCOUT)". The author thanks the Ohmsett staff for sample preparations and Roberta Dixon for the Mathcad analysis. The findings and opinions expressed in this paper are solely those of the author and do not necessarily reflect the views of the Bureau of Safety and Environmental Enforcement.

\section{References}

1. M. Fingas, "The challenges of remotely measuring oil slick thickness," Remote Sensing 2018, 10(2), 319 .

2. M.F. Fingas, "The basics of oil spill cleanup," $3^{\text {rd }}$ edition, CRC Press, ISBN 978-1-4398-6246-9, (2013).

3. M. Fingas, [Handbook of Oil Spill Science and Technology], Wiley, ISBN 978-0-470-45551-7, (2015).

4. J. Svejkovsky, M. Hess, J. Muskat, T.J. Nedwed, J. McCall, O. Garcia, “Characterization of surface oil thickness distribution patterns observed during the Deepwater Horizon (MC-252) oil spill with aerial and satellite remote sensing", Marine Pollution Bulletin 110, 162-176 (2016).

5. C. Hu, L. Feng, J. Holmes, G.A. Swayze, I. Leifer, C. Melton, O. Garcia, I. MacDonald, M. Hess, F. Muller-Karger, G. Graettinger, R. Green, “Remote sensing estimation of surface oil volume during 
the 2010 Deepwater Horizon oil blowout in the Gulf of Mexico: scaling up AVIRIS observations with MODIS measurements," J. Appl. Remote Sens. 12(2), 026008 (2018), doi: 10.1117/1.JRS.12.026008.

6. "ROVs and AUVs Collect Slick Thickness Measurements," The Ohmsett Gazette, (Spring/Summer 2017).

7. Sun, S.; Hu, C.; Feng, L.; Swayze, G.A.; Holmes, J.; Graettinger, G.; MacDonald, I.; Garcia, O.; Leifer, I. Oil slick morphology derived from AVIRIS measurements of the Deepwater Horizon oil spill: Implications for spatial resolution requirements of remote sensors. Marine Pollution Bulletin 2016, 103, 276-285.

8. T.H. Allik, R.E. Dixon, M. Roberts, M. Walters, T.J. Soyka, J. Cho, “Enhanced oil spill detection sensors in low-light environments", Proc. SPIE 9827, Ocean Sensing and Monitoring VIII, 98270B (May 17, 2016); doi:10.1117/12.2222064.

9. T.H. Allik, R.E. Dixon, L. Ramboyong, M. Roberts, P. Zinser, T.J. Soyka, “Enhanced Oil Spill Detection Sensors in Low-Light Environments," OSPR/Chevron Oil Spill Response Technology Workshop, Albert H. DeWitt Officer's Club, Alameda CA, https://www.wildlife.ca.gov/OSPR/Public-Meetings, (25 February 2015).

10. T.H. Allik, R.E. Dixon, L.V. Ramboyong, M. Roberts, T.J. Soyka, G. Trifon, L. Medley, “Novel Electro-Optic Imaging Technologies for Day/Night Oil Spill Detection", International Oil Spill Conference Proceedings, Vol. 2014, No. 1, pp. 299609, (May 2014).

11. T.H. Allik, R.E. Dixon, M. Walters, "Remote measurement of thick oil spill depth using thermal imagery," Proc. SPIE 10631, Ocean Sensing and Monitoring X, (25 May 2018); doi: 10.1117/12.2300266; https://doi.org/10.1117/12.2300266.

12. S. Myhr, G. Ax, J. Gill, L. LeClair, E. Sippel, M. Walters, T.H. Allik, R.E. Dixon, “Mapping and reconnaissance imager, night-enhanced, for sensing of contaminants, oil, and unseen threats (MARINE SCOUT)," Proc. SPIE 10631, Ocean Sensing and Monitoring X, (25 May 2018); doi: 10.1117/12.2303963; https://doi.org/10.1117.12.2303963.

13. M. Fingas, C. Brown, "Review of oil spill remote sensing," Marine Pollution Bulletin 83, 9-23, 2014

14. J. Svejkovsky, A. Lewis, J. Muskat, J.H.S. Andersen, S. Benz, O. Garcia-Pineda, "Rebuttal to published article "Review of oil spill remote sensing by M. Fingas and C. Brown", Marine Pollution Bulletin, 9391-2, March 2015.

15. F.P. Incropera, D.P. Dewitt, T.L. Bergman, A.S. Lavine, "Fundamentals of Heat and Mass transfer", $6^{\text {th }}$ ed., John Wiley and Sons, (2007).

16. A. Kasaeian, M. Sameti, and A.T. Eshghi, "Simplified Method for Night Sky Radiation Analysis in a Cool-Pool System." Sustainable Energy, vol. 2, no. 1 (2014): 29-34. doi: 10.12691/rse-2-1-6.

17. M. Luciuk, "Night radiative cooling: the effect of clouds and Relative Humidity", Tech. Print. Retrieved from www.asterism.org/tutorials/tut37\%20Radiative\%20Cooling. Pdf, (2012).

18. M.A. Goforth, G.W. Gilchrist, J.D. Sirianni, "Cloud effects on thermal downwelling sky radiance", Proc. SPIE 4710, Thermosense XXIV, (15 March 2002); doi: 10.1117/12.45

19. A.A. Allen, D.H. Dale, Galt, J.A., J.A. Murphy. "Effective Daily Recovery Capacity (EDRC) Project Final Report," Genwest System and Spiltec, Edmonds, WA, (7 December 2012). 